\title{
Knowledge, Practice and Associated Factors of Breast Self Examination Among Female Students of the College of Public Health and Medical Science, Jimma University, Ethiopia
}

\author{
Fitsum Desta $^{1}$, Abdulhalik Workicho ${ }^{2}$, Alemayehu Atomsa ${ }^{2}$, Desta Workneh ${ }^{3}$, Bosena Tebeje $^{3, *}$ \\ ${ }^{1}$ School of Medicine, College of Public Health and Medical Science, Jimma University, Jimma, Ethiopia \\ ${ }^{2}$ Department of Epidemiology, College of Public Health and Medical Science, Jimma University, Jimma, Ethiopia \\ ${ }^{3}$ School of Nursing and Midwifery, College of Public Health and Medical Science, Jimma University, Jimma, Ethiopia
}

Email address:

bosenatebeje@yahoo.co.uk(B. Tebeje)

${ }^{*}$ Corresponding author

\section{To cite this article:}

Fitsum Desta, Abdulhalik Workicho, Alemayehu Atomsa, Desta Workneh, Bosena Tebeje. Knowledge, Practice and Associated Factors of Breast Self Examination Among Female Students of the College of Public Health and Medical Science, Jimma University, Ethiopia. American Journal of Health Research. Vol. 6, No. 2, 2018, pp. 44-50. doi: 10.11648/j.ajhr.20180602.12

Received: December 31, 2017; Accepted: January 18, 2018; Published: March 28, 2018

\begin{abstract}
Back ground: Breast cancer is the most common cancer among women in many parts of the world. Facilities for screening and early detection are extremely limited in resource limited countries like Ethiopia, yet early diagnosis improves survival. Breast self-examination can help to detect it at an early stage. Our study examined the knowledge, practice and associated factors of Breast Self examination (BSE). Methods and materials: cross sectional study design was conducted among 200 female Medical, Health officer, Nursing and Midwifery students in Jimma University College of public health and medical science. Samples were selected using a systematic sampling technique. Pre-tested, structured, and self administered survey questionnaire abstracted and adapted from relevant literatures used to collect the required information. Analysis was done using chi-square test to assess the association between the dependent and independent variables and logistic regression to determine the effect of exposure variables on the outcome variables, using SPSS version 16:0 software. Result: The majority $(89 \% ; 95 \% \mathrm{CI}=84.7-93.3 \%)$ of participant students had good knowledge about Breast self examination but, only 42 (21\%) practice it correctly. After adjusting for potential socio-demographic confounders, multivariate logistic regression analysis showed: compared to rural residents, urban residents were more than 4 times ( $\mathrm{AOR}=4.19 ; 95 \% \mathrm{CI}=1.63,10.77 ; \mathrm{P}=0.003$ ); clinical year students compared to their pre-clinical counterparts were more than 5 times $(\mathrm{AOR}=5.34 ; 95 \% \mathrm{CI}=1.70,16.75$; $\mathrm{P}=0.004)$ more likely to have good knowledge about SBE. Similarly clinical year students were more than 7 times $(A O R=$ 7.24, 95\% CI=3.85, 13.59, P <0.001) more likely to practice SBE than pre-clinical students. Conclusion:: The majority of students had good knowledge about Breast Self Examination but only few practice it correctly, while more than 50\% never practiced it at all. Awareness creation campaign on BSE among young female students should be done at Reproductive Health Service clinics of the university.
\end{abstract}

Keywords: Breast Self-Examination, Female Students, Knowledge, Practice, Ethiopia

\section{Introduction}

Breast cancer appears to be a disease of both the developing and developed worlds. Carcinoma of the breast is an important public health problem with its associated high morbidity and mortality [1]. Current reports indicate that cancer of the breast is the most common malignancy in females affecting more than a million females annually with an increasing incidence as the women presumably adopt a western life style [2], [3]. Although the life time risk of breast cancer is about $10 \%$ for white women and $7.3 \%$ for black women, black women seem to develop the lesion at an 
earlier age [4], present with a bigger mass and late for treatment [5], [6]. Breast cancer reduces life expectancy of the population at risk especially those between thirty to fifty years. It has been predicted that $3.5 \%$ of this women will die from breast cancer [7].

A study in Turkey indicated that breast cancer is the second leading cause of cancer-related deaths among Turkish women [8]. In Nigeria, cancer of the breast has overtaken carcinoma of the cervix in hospital incidence. A preliminary survey report from population based epidemiological study in Nigeria showed the prevalence of breast cancer to be 116 cases per 100000 women per year [2]. Awareness of risk factors and early warning signs of the disease among different groups were below average [9], [10], [11].

Breast Self Examination (BSE) is an important, cheap and easy method for early diagnosis of breast cancer. Early diagnosis of breast cancer has a positive effect on the prognosis as well as limits the development of complications and disability. Furthermore, it improves quality of life and survival. In some studies, it has been reported that women who carefully examined their breasts could find small masses of breast cancer and their prognosis became better. For example, in a study carried out by Philip et al., 54.0\% of 304 patients with newly diagnosed breast cancer claimed to practice BSE [12]. In this study, it was found that those who performed BSE had reported their symptoms to health personnel sooner than the other subjects. In addition, in a meta-analysis of 12 studies including the study mentioned above, evidenced that there was good evidence of the benefit of encouraging women to practice BSE [13].

\subsection{The Extent of the Problem}

Breast cancer $(\mathrm{BC})$ is the most common cancer among females World-wide. Globally, there is a clear increment in the incidence of and mortality from Breast cancer in both developed and developing countries. The total number of new cases diagnosed annually exceeds one million and this is expected to increase in the coming years [14]. It causes 376,000 deaths a year worldwide; about 900,000 women are diagnosed every year with the disease [15]. Women in developing countries are facing an increasing threat to it in recent years due to different risk factors. According to the American cancer Society these risk factors include having history of Breast cancer in ones family ( $1^{\text {st }}$ degree relation), high fatty diet, alcohol consumption, Smoking...Etc [15].

According the report of Ethiopian cancer Association (ECA), although there is no cancer registry in Ethiopia, clinical records show that there are 120,500 cancer cases per year. The report also revealed that among the ten top cancers cases seen at Black Lion radiotherapy center: breast cancer stood $2^{\text {nd }}$ next to carcinoma of the cervix [16]. Breast selfexamination (BSE) is an important viable optional substitute available, for identifying breast tumors at an early stage, where access to clinical breast examination and mammograms is difficult. Thorough clinical examination and patient education in self-examination can have a crucial impact on early identification of breast cancer; its diagnosis and, ultimately, enhanced survival. According to American Cancer Society (ACS) recommendations, women starting from the early 20's should know how their breasts normally feel and report any breast changes promptly to their health care providers [8], [17]. In many countries, especially resource limited countries like Ethiopia; BSE will most likely be the only feasible approach to wide population coverage as it is a cheap and easy method. Facilities for screening and early detection are extremely limited yet early diagnosis improves survival. This study will explore the knowledge, practice and associated factors of Breast Self Examination among female undergraduate students in Jimma University CPHMS as a means of screening and early detection in a low resources environment.

\subsection{Justification}

The main methods of screening involve breast selfexamination (BSE), physical examination of the breasts by a physician or qualified health workers, clinical breast examination (CBE) and mammography. Early diagnosis usually results in treatment before metastasis and signifies a better outcome of management. As evidenced by many literatures the prevalence of breast cancer and lumps is increasing from time to time. Despite the advent of modern screening methods, more than $90 \%$ of cases of cancers of the breast are detected by women themselves [24], stressing the importance of breast self-examination.

In many countries, especially developing countries like Ethiopia, BSE will most likely be the only feasible approach to wide population coverage as it is a cheap and easy method. Being on the frontline of patient care specially, nurses, midwives and health officers are in a unique position as they have a supportive role in educating and motivating patients on BSE in the primary health care setting. Due to their key role in patient education, it was felt interesting to explore nurses, midwives, health officers and medical students' knowledge and practice on Self breast examination which may indirectly influence their patients' understanding and practice of it. Moreover, published documents in the area of BSE in Ethiopia are scarce. This study was therefore aimed at assessing the knowledge, practice and factors contributing to breast self-examination among female students and thereby proposed relevant recommendations.

\section{Materials and Methods}

\subsection{Study Area and Period}

The study was conducted in Jimma University which is located in Jimma town. Jimma town is $365 \mathrm{~km}$ south west of Addis Ababa, the capital city of Ethiopia. Jimma University established in 1999 which is one of the top higher learning universities in Ethiopia located in Oromia Region, Jimma zone. It offers programmed research which leads towards degree in different fields of study. The university consists six colleges i.e., college of Agriculture and Veterinary medicine, college of business and economics, college of Natural 
science, college of Social sciences and law, and college of public health and medical sciences, college of engineering and technology. The college of public health and medical sciences was established by the amalgamation of the former faculty of public health and faculty medical sciences and including the university specialized hospital in 2009 by the business process re-engineering undertaken in the university.

Under the college public health and medical science there are eight undergraduate programs including Medicine, Health Officer, Nursing, Midwifery, Anesthesia, Pharmacy, and Medical Laboratory and Environmental health. Among the above mentioned departments in the college, female students in Medicine, Health Officer, Nursing and Midwifery departments were selected for this study because of the fact that the nature of their profession on regards of BSE, they are the ones who have a direct relationship and likely teaching clients while carrying out their promotive and preventive activities at the different health care setting.

\subsection{Study Design}

A cross sectional study design was conducted among all female Nursing, Midwifery, Health officer and Medicine students enrolled in Jimma University College of Public Health and Medical Sciences (CPHMS) in 2011/ 2012.

\subsection{Sample Size and Sampling Techniques}

Sample size was determined by using single population proportion formula and the following assumptions:

$$
\mathrm{Ni}=\left(Z^{\alpha} / 2\right)^{2} \mathrm{p}(1-\mathrm{p}) / \mathrm{d}^{2}
$$

Where; e

ni- initial sample size required

Z- Standard normal variable at $95 \%$

P- Estimation of practice of BSE $=0.5$ (there was no published studies on this topic and to get the maximum sample size)

d- Margin of error $(\mathrm{d}=5 \%)$

$\mathrm{N}$ - Total member of female students (417), and since the total population is 417 , we use population correction formula as shown below, the final sample size become 200 .

$$
\frac{(1.96)^{2}(0.5)(0.5)}{0.05^{2}}=384 ; \mathrm{Nf}=\frac{384}{1+384 / 417}=200
$$

From the total study population 417 , the study subjects (200) were picked by using systematic sampling technique, using their attendance as a sampling frame, stratified by the department and level of education. The sample was proportionally allocated to each level and department.

\subsection{Data Collection Instruments and Procedures}

The independent variables were: Age, Residence, Religion, Ethnicity, field of study, level of students (preclinical/ clinical) and dependent variables were Knowledge of SBE; Practice of SBE. A structured interviewer administered questionnaires were used to collect the data.
These tools were developed after reviewing relevant literatures and similar studies. Prior to data collection three medical students were selected for data collection and trained by principal investigator.

Operational definition/measurements

1. Good Knowledge about SBE- those who correctly answered $\geq 60 \%$ of knowledge questions

2. Poor knowledge- those who correctly answered $<60 \%$ of knowledge questions

3. Correct Practice of SBE- those who checked or perform SBE a week after each menses

4. Incorrect practice of SBE - those who practice SBE other than the correct time in the cycle

5. Do not practice SBE at all-those who never check their breast at all in the cycle

6. Regular practice of BSE- those who practice SBE at the correct time in the cycle (at least Ones/month after menses)

\subsection{Data Quality Control}

In order to maintain the quality of data collection instruments' discussion was held with data collectors and researchers to have common understanding. Before the actual data collection, pre-test was done on $5 \%$ of the total sample from other department students. The purpose of the pretesting was to ensure validity and reliability of measuring tools; respondents were able to understand the questions and to check the wording. Amendment was be made accordingly after pre-testing. During data collection each questionnaire was checked for completeness by the researcher.

\subsection{Data Analysis}

All data from the filled questionnaires were coded, entered and cleaned using SPSS version 16:0 In addition to descriptive statistics, chi-square test and logistic regression analysis was considered to assess the association between dependent and independent variables of the study. P-value less than 0.05 was considered statistically significant.

\subsection{Ethical Consideration}

Ethical clearance letter was received from Jimma University students research project (SRP), college of public health and medical science. Verbal and written consent was obtained from respondents. Participants were ensured on anonymity, privacy and confidentially of information throughout the study process.

\section{Results}

A total of 200 female students participated in this study, with a response rate of $100 \%$. The majority $127(63.5 \%)$ of participants were in the age group of 21-25 years, Orthodox Christian constituted 119 (59.5\%), students sourced from urban were $151(75.5 \%), 98$ ( 49\%) were medical students and $104(52 \%)$ were in their clinical year (Table 1). 
Table 1. Socio-demographic characteristics of study participants at Public Health and Medical Science College (N=200), Jimma University.

\begin{tabular}{|c|c|c|}
\hline & Frequency & $\%$ \\
\hline \multicolumn{3}{|l|}{ Age group } \\
\hline $15-20$ & 67 & 33.5 \\
\hline $21-25$ & 127 & 63.5 \\
\hline $26-30$ & 6 & 3.0 \\
\hline \multicolumn{3}{|l|}{ Religion } \\
\hline Orthodox & 119 & 59.5 \\
\hline Muslim & 32 & 16.0 \\
\hline Protestant & 46 & 23.0 \\
\hline Others & 3 & 1.5 \\
\hline \multicolumn{3}{|l|}{ Residence } \\
\hline Rural & 49 & 24.5 \\
\hline Urban & 151 & 75.5 \\
\hline \multicolumn{3}{|l|}{ Field of study } \\
\hline Medicine & 98 & 49.0 \\
\hline health officer & 42 & 21.0 \\
\hline Nursing & 50 & 25.0 \\
\hline Midwifery & 10 & 5.0 \\
\hline \multicolumn{3}{|l|}{ Level of study } \\
\hline Pre-clinical year & 96 & 48.0 \\
\hline Clinical year & 104 & 52.0 \\
\hline
\end{tabular}

The majority, 178 (89\%) of participant students had good knowledge on Breast Self Examination (Table 2), but only 42 (21\%) practiced it correctly while, 51 (25.5\%) practice it incorrectly and 107 (54\%) of them never practiced it at all. As indicated in Table 2, statically significant association was observed between residence and level of students and knowledge. Moreover, level of students and practice of BSE were significantly associated, $(\mathrm{P}<0.05)$.

Table 2. Knowledge and practice of Breast Self-Examination and associated factors among female students at Public Health and Medical Science College, Jimma University.

\begin{tabular}{|c|c|c|c|c|}
\hline Variables & & & $X^{2}$ & P-value \\
\hline & $\begin{array}{l}\text { Level of Knowledge } \\
\text { Good Knowledge }(\mathrm{N}=178)\end{array}$ & Poor knowledge (N=22) & & \\
\hline \multicolumn{5}{|l|}{ Residence } \\
\hline Rural & 37 & 12 & 12.064 & 0.001 \\
\hline $\begin{array}{l}\text { Urban } \\
\text { Level of students }\end{array}$ & \multicolumn{3}{|c|}{ Level of studentsy } & \\
\hline Pre- clinical year & 78 & 18 & 11.326 & 0.001 \\
\hline Clinical year & $\begin{array}{l}100 \\
\text { Practice of SBE }\end{array}$ & 4 & & \\
\hline Residence & Practice SBE (N=93) & Do not practice $\mathrm{SBE}(\mathrm{N}=107)$ & & \\
\hline Rural & 24 & 25 & 0.160 & 0.689 \\
\hline Urban & 69 & 82 & & \\
\hline \multicolumn{5}{|l|}{ Level of students } \\
\hline Pre-clinical year & 22 & 74 & 41.274 & 0.001 \\
\hline Clinical year & 71 & 33 & & \\
\hline
\end{tabular}

Ninety three (46.5\%) of students reported to have practicing BSE, among which, only 42 (21\%) practiced it regularly/once in a month. 19 (9.5\%) of participants claimed to have found breast lump of which only 11 (57.9\%) consulted health care professionals (Table not shown).

Statistically significant association was also observed between residence, level of students, and knowledge of BSE, and level of students was significantly associated with practice of Breast Self Examination, $(\mathrm{P}<0.05)$. After adjusting for potential socio-demographic factors, multivariate logistic regression analysis showed, compared to rural residents, urban residents were more than 4 times $(\mathrm{AOR}=4.19 ; 95 \% \mathrm{CI}=1.63,10.77 ; \mathrm{P}=0.003)$; clinical year students compared to pre-clinical ones more than 5 times
( $\mathrm{AOR}=5.34 ; 95 \% \mathrm{CI}=1.70,16.75 ; \mathrm{P}=0.004)$ more likely to have good knowledge on SBE. Similarly clinical year students were more than 7 times $(\mathrm{AOR}=7.24,95 \% \mathrm{CI}=3.85$, 13.59 , $\mathrm{P}<0.001)$ more likely to practice SBE than preclinical students, (Table3).

The major reasons for not practicing Breast Self Examination mentioned by the participants were negligence (37.4\%) followed by do not know how to do it (26.2\%), (Figure 1). 


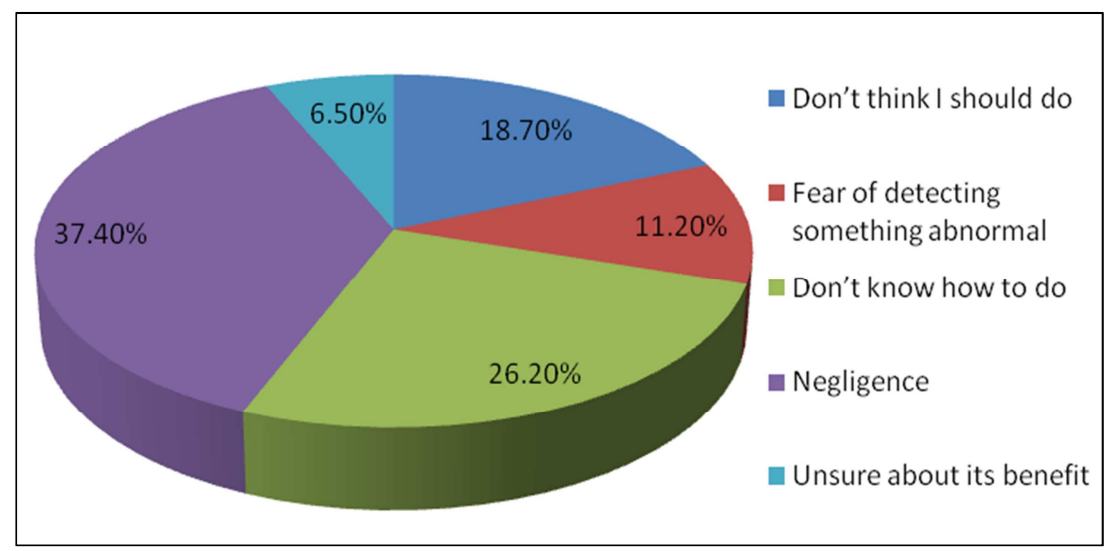

Figure 1. Reasons for not practicing BSE among female students at Public Health and Medical Science College, Jimma University.

Table 3. Factors associated with the Knowledge and Practice of Breast Self Examination.

\begin{tabular}{llccc}
\hline Variable & & COR (95\%CI) & *AOR (95\%CI) & P. V \\
\hline Knowledge about SBE & Urban (Ref, Rural) & $4.57(1.83,11.41)$ & $4.19(1.63,10.77)$ & 0.003 \\
$\begin{array}{l}\text { Residence } \\
\text { Level of students }\end{array}$ & Clinical level (Ref, Pre-clinical) & $5.77(1.88,17.74)$ & $5.34(1.70,16.75)$ & 0.004 \\
$\begin{array}{l}\text { Practice about SBE } \\
\text { Level of students }\end{array}$ & Clinical level (Ref, Pre-clinical) & $7.24(3.85,13.59)$ & $7.24(3.85,13.59)$ & $<0.001$ \\
\hline
\end{tabular}

*Adjusted odds ratio (AOR)- adjusted for age, religion and field of study; Ref-reference.

\section{Discussion}

Many literatures evidenced that the prevalence of breast cancer and lumps is increasing from time to time [19], [27], [28], [29] Despite the advent of modern screening methods, more than ninety percent of cases of cancer of the breast are detected by women themselves, stressing the importance of breast self-examination. In many countries, especially developing countries like Ethiopia, Breast Self Examination will be most likely and the only feasible approach to a wider population coverage as it is a cheap and easy method. With this assumption, knowledge, practice, reasons and associated factors of BSE among female students was assessed.

This study identified that the majority (89\%) of participant students had good knowledge about Breast Self Examination. Similarly a study in Kampala University depicted that among the total 314 female student participants, $81.5 \%$ had a high awareness of Breast Self Examination [20]. The slight difference observed between the two studies might be due to the difference in the sample size and the current concern on non communicable diseases including breast cancer in developing countries.

With regard to the practice of Self Breast examination, the current study showed only 42 (21\%) of participants perform it correctly while $51(25.5 \%)$ practice it incorrectly and 107 $(54 \%)$ of them never practiced it at all. Similar a study in Kampala University showed that among a total 314 female students, $30 \%$ of them had ever performed Breast self Examination, $14 \%$ performed it regularly, $8 \%$ knew the correct monthly timing. $4.8 \%$ found to have breast lumps [20]. Another study in Malaysia showed that 87 (36.7\%) undergraduate female students claimed to have practiced Breast Self Examination, while $63.3 \%$ of them did not practice it [21]. A more recent study done in Cameroon among undergraduate students showed, only $3 \%$ had performed BSE regularly [30]. All these studies indicated that although participants have good knowledge and awareness about Breast Self Examination, the practice of it is low. This again signals that if we are going to make any headway in the prevention of mortality and morbidity from breast cancer, there is an urgent need for working on behavioral change among female students in tertiary institutions on the practice of Breast self examination.

As most literatures evidenced knowledge and consistent (monthly breast self-examination) practice could protect women from severe morbidity and mortality due to breast cancer [16], [17]. Correct practice of BSE involves a number of aspects including; frequency, timing, a correct technique, consistent application of it as well as acting on any positive findings without much delay. However there is a variation in on the knowledge and practice of SBE across different regions and localities. In this study $93(46.5 \%)$ of students reported to have practicing BSE, among them only $42(21 \%)$ practiced it regularly/once in a month. The major reason as for not practicing BSE mentioned was negligence (37.4\%) followed by do not know how to do it $(26.2 \%)$. A more recent study in Ethiopia confirmed that among 420 female university students, only $28.3 \%$ performed BSE [31]. Another study in Turkey indicated that only $17 \%$ doing BSE on monthly basis [18]. The difference might be due to the difference in the socio-demographic characteristics of the study subjects and time of study.

After adjusted for potential socio-demographic factors; residence and level of students were independently positively associated with the knowledge of BSE; also level of students and practice of BSE were positively and significantly 
associated. A similar study done on nursing students in Saudi Arabia identified a significant relation between nursing students BSE practice and their academic experience/level [26]. Possible explanation for clinical year students were more likely to have good knowledge and practice BSE, might be due to the fact that when these students reach clinical year they may gain more information as part of their courses and become more aware of the importance of BSE which would inspire them to practice it.

As evidenced by many studies, one potentially important strategy in reducing breast cancer mortality is breast cancer screening to achieve earlier detection of cancer [22], [23]. The main methods of screening involve Breast selfexamination. Physical examination of the breasts by a physician or qualified health workers, clinical breast examination and mammography. Early diagnosis usually results in treatment before metastasis and signifies a better outcome of management. Despite the advent of modern screening methods, more than $90 \%$ of cases of cancers of the breast are detected by women themselves [24], which still implies on the importance of breast self-examination.

\section{Conclusion}

This study revealed that although most of participants had good knowledge on BSE, however, its practice was very low. The major reasons for not practicing BSE mentioned were, negligence $(37.4 \%)$, followed by do not know how to do it (26.2\%). About 1 in 10 of participants claimed to have found breast lump but only $58 \%$ of them consulted health care professionals for it. Residence and level of study were significantly and positively associated with good knowledge of BSE. Statistically significant association was also observed between level of study and practice of BSE. In order to function as effective promoters for the prevention of breast cancer through early detection, they must possess not only the relevant knowledge but also appropriate practice and act as role models for the rest of public.

Health care workers at university student clinics should create BSE awareness campaign among young female students to encourage them to practice BSE and report any unusual changes in their breasts to the reproductive health clinics. Finally, this study, being cross sectional design, it does not show cause and effect relationship. While more comprehensive population-based longitudinal studies are recommended in the future.

\section{Acknowledgements}

Jimma University, data collectors and participants deserves acknowledgments for their collaboration. We are also grateful to colleagues for their valuable comments and contributions.

\section{Conflict of Interest}

The authors declared that they have no competing interests.

\section{Appendix}

\section{Abbreviations}

BSE- breast self-examination; WHO- World health organization; CBE-clinical breast examination; ACSAmerican Cancer Society; BC-Breast cancer; ECA-Ethiopian cancer Association; PC- pre-clinical; SPSS- Statistical package for Social sciences; CPHMS - college of Public health and medical sciences

\section{References}

[1] Maurer FA. Peer education model for teaching breast selfexamination to undergraduate College women. 1997; 20.

[2] Forbes JF. The incidence of breast cancer. The global burden, public health considerations. Journal of Oncology. 1997; 24 (1):20-35.

[3] Ruiz-Ramos M. Viciana Fernandez F. The trends and geographical distribution of breast cancer mortality in Andalusia. Aten Primaria. 1997; 20.

[4] Newman LA, Alfonso AE. Age related differences in breast cancer stage at diagnosis between black and white patients in an urban community hospital. Ann Surg. Oncology. 1997; 4.

[5] Adebamawo CA, Ajayi OO. Breast Cancer in Nigeria. West Afr J Med. 2000; 10:179-191.

[6] Edino ST, Ochicha O, Alhassan S, Mohammed AZ, Ajayi OO. Clinico-Pathological Review of Breast Cancer in Kano. Nigerian Journal of Surgery. 2000; 7:70-75.

[7] Adebamawo CA, Adekunle OO. Case-controlled study of the epidemiological risk factors for breast cancer in Nigeria. Br J Surg. 1999; 86:665-668.

[8] Pınar E Dündar, Dilek Özmen, Beyhan Öztürk, Gökçe Haspolat, Filiz Akyıldız, Sümeyra Çoban and Gamze Çakıroğlu. The knowledge and attitudes of breast selfexamination and mammography in a group of women in a rural area in western Turkey. Available at: http://www.biomedcentral.com/1471-2407/6/43.

[9] Baines CJ. Breast Self Examination. Cancer. 1992; 69.

[10] Ncarubara RG. Control of Breast cancer using health education. East Afr Med J. 1999; 76:661-663.

[11] Michielutte R, Diseker R, Hayes D. Knowledge of cancer, a cross cultural comparison among students in the U.S. and U.K. Int J Health Educ. 1979; 2:42-48.

[12] Philip J, Harris G, Flaherty C, Joslin CAF. Clinical measures to assess the practice and efficiency of breast selfexamination. Cancer. 1986; 58:973-977.

[13] Hill D, White V, Jolley D, Mapperson K. Self examination of the breast: Is it beneficial? Meta analysis of studies investigating breast self examination and extent of disease in patients with breast cancer. BMJ. 1988; 297:271-277.

[14] Ahmed B. A. Awareness and Practice of Breast Cancer and Breast-self Examination among University Students in Yemen. Asian Pacific Journal of Cancer Prevention, Vol. 11, 2010. 
[15] World Health Organization. The World Health Report. Conquering Suffering, Enriching Humanity, Report of the Director General. WHO, Geneva. 1997; 22.

[16] Ethiopian cancer Association (ECA). Available at: http://www.yeeca.org/Cancer\%20in\%20Ethiopia.htm.

[17] American Cancer Society, 2005. "How is breast cancer found," Available at: http://www.cancer.org/docroot/CRI/content.

[18] International Journal for cancer. The Knowledge and Practice of Breast Self-examination among Health Care Workers in Kayseri, Turkey. September/October 2009 - Volume32. Available at: journals.lww.com/.../The_Knowledge_and_Practice_of_Breast .15.asp.

[19] Owoaje M. O. B. Knowledge and Practice of Breast SelfExamination among Female Traders in Ibadan, Nigeria. Annals of Ibadan Postgraduate Medicine. 3 (2), 2005.

[20] 20. Obaikol R, Galukande M, Fualal J. Knowledge and Practice of Breast Self Examination among Female Students in a Sub Saharan African University. Mulago Hospital, Kampala, Uganda. East and Central African Journal of Surgery, 15 (1), 2010:22-27.

[21] Zavare M. A, Juni M. H, Manaf R. A, Ismail I. Z, Said S. knowledge on breast cancer and practice of breast self examination among selected female university students in Malaysia. Medical and Health science journal. Vol 7. 2011:4856 .

[22] A. Reeler, Y. Qiao, L. Dare, J. Li, A. L. Zhang, and J. Saba, "Women's cancers in developing countries: from research to an integrated health systems approach," Asian Pacific Journal of Cancer Prevention, 2009.10 (3).
[23] Timothy D. Dye, Solomon Bogale, Claire Hobden, Yared Tilahun, Teshome Deressa, and Anne Reeler. Clinical Study Experience of Initial Symptoms of Breast Cancer and Triggers for Action in Ethiopia. Volume 2012. 2011. International Journal of Breast Cancer.

[24] Rosemary B. Bassey, Nicholas K. Irurhe, Modele A. Olowoyeye, Adekunle A. Adeyomoye, Adebayo T. Onajole. Knowledge, attitude and practice of Breast self examination among nursing students in Lagos University Teaching Hospital, Nigeria. International Research Journals. 2011.

[25] Steps of BSE. Available at: http://www.99healthplus.com/2012/five-steps-of-breastcancer-self- examination/.

[26] Alsaif AA. Breast self-examination among Saudi female nursing students. Saudi Arabia. Saudi medical journal. 2004; 25 (11):1574-8

[27] Ferlay J, Soerjomataram I, Ervik M, et al. Estimated Cancer Incidence, Mortality and Prevalence. Worldwide. 2012.

[28] Global Burden of Disease Cancer Collaboration. The global burden of cancer 2013. JAMA Oncol 2015.

[29] World Health Organization. Breast cancer: prevention and control. Geneva, Switzerland: WHO; 2013.

[30] Nde FP, Assob JC, Kwenti TE, et al. Knowledge, attitude and practice of breast self- examination among female undergraduate students in the University of Buea. BMC Research Notes (2015) 8:43.

[31] Birhane K, Alemayehu M, Belayneh Anawte B, et al. Practices of Breast Self-Examination and Associated Factors among Female Debre Berhan University Students. International Journal of Breast Cancer. 2017. 